\title{
How to Empower the Workforce - Analyzing Internal Crowd Work as a Neo-Socio-Technical System -
}

\author{
David Durward \\ University of Kassel \\ david.durward@uni-kassel.de \\ Ivo Blohm \\ University of St.Gallen \\ ivo.blohm@unisg.ch
}

\author{
Benedikt Simmert \\ University of Kassel \\ benedikt.simmert@uni-kassel.de \\ Jan Marco Leimeister \\ University of St.Gallen \\ \& University of Kassel \\ janmarco.leimeister@unisg.ch
}

\author{
Christoph Peters \\ University of St.Gallen \\ \& University of Kassel \\ christoph.peters@unisg.ch
}

\begin{abstract}
In this paper, we analyze internal crowd work as Neo-STS from an employee's perspective. Based on qualitative interviews, we describe in our model how employees perceive empowerment through participation in internal crowd work. As our main contribution, we detail and extend existing research regarding internal crowd work, Neo-STS as well as empowerment by identifying structural antecedents that affect psychological empowerment of internal crowd workers.
\end{abstract}

\section{Introduction}

Digitization combines the activities of our society and enables a profound change in working structures. As a result, value creation increasingly takes place in dynamic environmental contexts [1], whereby new digital forms of work emerge that radically reshape workflows and processes [2]. Moreover, organizations invest more and more in collaboration technologies to leverage the intellectual resources embedded in their employees and form respective working groups [3]. A well-known example of these collaborative teams refers to Hackathons which describe events where people, who are not normally collocated converge for a few days to write code together [4]. However, in recent years, companies are increasingly using IT platforms to engage employees, accelerate collaboration, and encourage ideas within the company [5]. As a new form of work and collaboration, crowd work reflects digital gainful employment based on the crowdsourcing principle, in which an undefined mass of people processes digital goods via an open call on IT-based platforms in return for payment [6].
While crowd work has its roots in external application, the mechanisms of crowd work are increasingly being used within the boundaries of the company. This internal form of crowd work relates to an IT-based group activity that is based on an open call for participation within a company [7]. In such internal settings, the own employees (alias internal crowd worker) act as an internal crowd and process tasks, ideas, and projects on an IT-based platform. Thereby, any participation is paid indirectly via the employees' regular employment contract [6]. Thus, internal crowd work describes a special case of social-technical systems that produces informational products and/or services for internal or external customers by harnessing the potential of crowds [8].

Several well-known enterprises, including Google, AT\&T, Deloitte, and IBM, applied internal crowd work. Besides solving several types of decision support problems by crowd intelligence approaches, design activities [7], or software testing [9], companies pursue the goal of becoming more agile with the help of internal crowd work. However, the successful application and execution of internal crowd work depends on efficient work structures and an empowered workforce [10]. Therefore, the crowd worker as the processing agent of tasks and projects must be analyzed comprehensively. However, few studies have been conducted to address the individuals working in the crowd, their experiences, and perceptions [11, 12]. One well-established construct that is associated with the individuals' perception of work is empowerment. Prior information systems (IS) research examined the emergence of empowerment among employees and further found it to enhance organizational performance and work satisfaction [13]. In this regard, a systematic empowerment can be considered as an important factor for the efficient use of internal crowd work [10]. Internal crowd work 
differs from traditional work settings in work execution via IT-based platforms including decomposition and aggregation of tasks. Since internal crowd work has unique characteristics that distinguish it from hierarchical work [7], we address the indicated gap by analyzing the perception of internal crowd work from an individual's perspective. More specifically, we focus on empowerment as a form of an employee's perception and explain structural characteristics that influence empowerment. Thus, this qualitative study addresses the following research question:

How does internal crowd work affect employees' perception of work?

\section{Theoretical background}

\subsection{Neo-socio-technical systems}

As a well-established theoretical lens, the underlying idea of socio-technical systems (STS) presumes that an organization or a work unit is a combination of social and technical elements [14]. Prior IS research builds on the STS approach by jointly optimizing the technology and related aspects with a focus on the overall user conditions within organizations [15, 16]. In this context, Bostrom and Heinen [17] introduced an analytical framework consisting of four interacting components. While two pertain to the social elements ("structure" and "people"), the other two describe the technical elements ("technology" and "tasks"). According to Lyytinen and Newman [18], tasks, actors, structure, and technology interact with each other and are embedded in the organizational environment that is driving and influencing change.

With the rise of digitization, work is no longer tied to one single organization acting as a container, in which both the work that is done and the infrastructure used to do it is encapsulated [15]. New technologies facilitate the emergence of novel work arrangements that increasingly take place outside organizational boundaries. Therefore, in recent IS research Winter et al. [15] provide an updated neo-socio-technical system (Neo-STS) approach that acts as a conceptual basis for IS scholars addressing emerging work trends and phenomena like internal crowd work. The traditional analytical framework is extended by four additional components ("multi-encapsulation"; "complex interrelation of socio-technical elements"; "multidirectional inheritance"; "continual negotiation"). First, multi-encapsulation refers to the trend that work systems are necessarily encapsulated within one or more STS [15]. As a result, socio-technical elements can span multiple containers. These containers, in turn, consider the people, resources, activities, goals, information, and technical artefacts that comprise the work system but simultaneously exist in various social systems [15]. Second, complex interrelation of sociotechnical elements describes the fact that work systems have interrelated, redundant, competing, or conflicting social and technical elements that may co-exist without ever being fully reconciled [15]. Therefore, one can observe a more complex interrelation of sociotechnical elements as dynamic mutually reinforcing components or as redundant substitutes [15]. Third, due to multi-directional inheritance, work systems can derive purpose, meaning, and structure from the multiple contexts in which elements are embedded. Further, they may pass on purpose, meaning, and structure to the socio-technical systems that emerge around them as well [15]. Fourth, the continual negotiation includes the fact that creation and continued existence of work systems involve simultaneous support for both work performance and ongoing negotiation of goals, and values [15].

In IS research, internal crowd work describes a particular Neo-STS that produces informational products and/or services, based on IT-enabled group activities, for internal or external customers by harnessing the potential of internal crowds [15]. Internal crowd work takes place in trans-organizational information infrastructures throughout the whole group [e.g., 9] and includes complex interrelations between various people, activities, and IT [19]. Based on the idea of multi-directional inheritance, internal crowd work initiatives are formed by different groups, locations, or departments and in turn positively affect the overall knowledge quality in the whole enterprise [20]. Furthermore, internal crowd work evolves constantly due to continual negotiation of the participants and thereby facilitates internal organizational learning [19].

\subsection{Empowerment}

In general, empowerment describes “....any increase in worker power (through, for example, increased formal authority or greater access to more useful information) that enables workers (and, collectively, the organization) to achieve institutional objectives with greater efficiency and effectiveness" [21]. Based on this definition, prior literature distinguishes between two perspectives in empowerment theory, the (socio-) structural and the psychological approach of empowerment [22]. First, the (socio-) structural approach focuses on empowerment as structures, policies, and practices regarding the targeted transformation and adaptation of organizational structures. This approach aims to give 
employees a greater scope for action and decision making as well as better access to information, resources, and opportunities for development [22].

In contrast to organizational structures, Conger and Kanungo [23] introduced the perspective of psychological empowerment. This perspective examines individual experiences as well as intrinsic motivational aspects of the employee [24]. Here, the subjective and individual interactions of the employees with the given structures are examined [22]. According to Spreitzer [24], empowerment is manifested in a set of four cognitions reflecting an individual's orientation to their work role: meaning, competence, selfdetermination, and impact. Meaning describes the value of a work goal or purpose, judged in relation to an individual's own ideals or standards [25]. Competence resembles an individual's belief in their capability to perform activities with skill [26]. The cognition of self-determination is defined as an individual's sense of having choice in initiating and regulating actions [27]. Lastly, the fourth cognition reflects the impact as the degree to which an employee can influence strategic, administrative, or operating outcomes at their work context [28].

In sum, the organizational or contextual structures of the structural empowerment approach influence the individual psychological empowerment of the employee. However, only by the simultaneous inclusion of both approaches, can the desired positive empowerment-induced effects be established [22]. In our context, an empowered workforce describes employees who can take more initiative and make own decisions to find solutions for overarching institutional problems through their participation in internal crowd work. Thus, this kind of empowerment is based on effects of the implementation of internal crowd work as a new form of work organization.

\section{Research method}

\subsection{Research context and data collection}

Although internal crowd work always needs a casespecific analysis since it occurs in various facets, in our study it describes the voluntary participation in internal projects besides regular workload. Therefore, to develop our theoretical model, we investigated internal crowd workers in three different global organizations. The first is a multi-national automotive corporation that has introduced internal crowd work initiatives since 2016 with the aim to be more agile. The second case describes the project of a globally-operating software developer. In this context, the overarching aim of the implementation has been the optimization of existing business processes. The third organization is another global player within the automotive industry and applied internal crowd work to improve knowledge exchange in the organization. Although there are slightly different reasons for the implementation, all cases have the constitutive characteristics of internal crowd work. All three cases describe settings in which employees perform an IT-enabled activity based on an open call for participation in an enterprise [6, 7]. With the aim of preventing elite bias [29], we have chosen these three different organizations to overcome biases resulting from a single case and to address the diversity of internal crowd work initiatives.

Our primary data source consists of 16 semistructured interviews. These kinds of interviews are well suited for exploring attitudes, values, beliefs, and the views of a person towards a phenomenon of interest [30]. We designed an open-ended interview protocol that focuses on the socio-technical elements as well as the perception of internal crowd work. The interviews took place between May and November 2017. Every single interview lasted between 30 and 90 minutes and was either conducted via telephone or Skype or even in face-to-face meetings. Subsequently, the interviews have been transcribed, coded, and analyzed by using the analysis software ATLAS.ti.

Since we aim to provide an unbiased data basis, we constructed a maximum variation sample that allows to identify essential features of a phenomenon (i.e., internal crowd work) as experienced by diverse stakeholders among varied contexts (i.e., employees of three organizations) [31]. Hence, we selected employees who differ regarding their function, position, age, and length of service.

\section{Table 1. Selection of crowd worker}

\begin{tabular}{|c|c|c|c|}
\hline $\begin{array}{c}\text { Crowd } \\
\text { Worker }\end{array}$ & $\begin{array}{c}\text { Organization } \\
\text { (Type of Project) }\end{array}$ & $\begin{array}{c}\text { Age } \\
\text { (Gender) }\end{array}$ & Department \\
\hline$C W 1$ & \multirow{6}{*}{$\begin{array}{l}\text { Alpha } \\
\text { (IT-platform for } \\
\text { collaborative } \\
\text { problem solving } \\
\text { of everyday } \\
\text { problems) }\end{array}$} & $52(f)$ & Sales \\
\hline$C W 2$ & & $56(\mathrm{~m})$ & IT \\
\hline$C W 3$ & & $42(f)$ & Supply Chain \\
\hline$C W 4$ & & $48(f)$ & After Sales \\
\hline$C W 5$ & & $58(\mathrm{~m})$ & After Sales \\
\hline CW6 & & $53(\mathrm{~m})$ & Supply Chain \\
\hline$C W 7$ & \multirow{5}{*}{$\begin{array}{l}\text { Beta } \\
\text { (IT-platform for } \\
\text { cross-functional } \\
\text { ideation and } \\
\text { innovation) }\end{array}$} & $35(\mathrm{~m})$ & Marketing \\
\hline$C W 8$ & & $39(f)$ & HR \\
\hline CW9 & & $46(f)$ & Sales \\
\hline CW10 & & $35(\mathrm{~m})$ & IT \\
\hline$C W 11$ & & $45(f)$ & Development \\
\hline$C W 12$ & \multirow{5}{*}{$\begin{array}{l}\text { Gamma } \\
\text { (IT-platform for } \\
\text { complex cross- } \\
\text { functional } \\
\text { projects) }\end{array}$} & $30(\mathrm{~m})$ & Accounting \\
\hline$C W 13$ & & $37(\mathrm{~m})$ & IT \\
\hline CW14 & & $37(\mathrm{~m})$ & Management \\
\hline CW15 & & $43(f)$ & Admin \\
\hline CW16 & & $51(f)$ & Work Council \\
\hline
\end{tabular}




\subsection{Data analysis}

In line with the existing body of knowledge [e.g., 32], we apply the well-established approach of Gioia et al. [33] to analyze our qualitative data. This methodology basically consists of two separate analysis phases. Within a first iteration, the analysis follows interviewee-centric terms and concepts in an inductive fashion (1st-order analysis). In the phase of the 1st-order analysis, a myriad of terms, codes, and concepts emerged in the analysis process. Looking for similarities and relations among the many identified codes, we reduced the number of codes to a manageable amount by relating them to concepts. Moreover, we tried to focus on concepts and tentative relationships emerging from the interviews to develop a comprehensive compendium of 1st-order terms. Thereby, concepts describe vaguely specified notions that capture basic qualities of a phenomenon. [33]

In a second step, we subsequently organized the 1st-order concepts into 2nd-order (theory-centric) themes and distilled them into overarching theoretical dimensions. These emerging 2 nd-order themes indicate concepts that might help to explain the observed phenomena. Then, we distilled the 2nd-order themes even further into aggregate dimensions [33]. After the initial stages of data analysis, we began cycling between our emergent data, themes, concepts, and dimensions as well as the relevant literature [33]. Thus, we included the Neo-STS approach, whereby data and existing theory were considered in tandem [34].

In sum, having the 1st-order concepts, the 2ndorder themes as well as the aggregate dimensions, the foundation for building a data structure is provided. Besides its visualization, this data structure describes the process from raw data to terms and themes in conducting the analysis and, thus, is an essential part of demonstrating rigor in qualitative research [35]. Afterwards, we shaped dynamic relationships among the 2nd-order concepts in the data structure and transformed these insights into a theoretical model [33]. The main object of building models is how to account for not only all the major emergent concepts, themes, and dimensions, but also for their dynamic interrelationships [33].

\section{Results}

\subsection{Constitutive elements of a theoretical model}

As mentioned above, we provide the essential groundwork for theory-building by developing our data structure (see Figure 1). It includes 1st-order concepts that are meaningful to the employees as internal crowd workers and 2nd-order themes that are extracted overarching themes. Both iterations finally enabled us to assemble the aggregated dimensions.

4.1.1. Multi-encapsulation. Our findings provide information about several locations where traditional boundaries erode. We observed an ongoing encapsulation of multiple units, departments, and even organizations within the whole group in consequence of implementing internal crowd work projects. Since the employees interact via an IT-facilitated platform, they can easily form own globally distributed teams without using the whole group infrastructure for this formation process. By doing so, a new interorganizational network as a separate work system emerges that consists of several existing social subsystems (e.g., units, divisions, departments). As mentioned: "We process, forward and even delegate global problems via that new network." (CW7) This reconfiguration of work contexts brings together employees of different hierarchies, responsibilities as well as skills and, thereby, makes existing solutions and best practices accessible for the whole group.

Furthermore, the companies integrate external service providers like SAP, IBM, and T-Systems in their internal crowd work project initiative. On the one hand, they provide the required IT-infrastructure (i.e., platform, software, interfaces). On the other hand, these providers are essential external partners who supply the internal crowd work initiative with an additional pool of external experts and equipment. However, this removal of organizational containers and boundaries also bears risks since the existing work processes can be very different among the collaborating units. For example, the process of purchasing varies widely from one subsidiary to another, which leads to additional expenses of coordination to jointly optimize the purchasing software via the internal crowd.

\subsubsection{Complex interrelation of socio-technical} elements. Since the internal crowd consists of different cultures, languages, habits, and working methods, additional workload regarding coordination, communication and allocation emerges. In fact, further capacities are needed to select the internal crowd workers, decompose and subsequently aggregate the tasks, and finally implement the solutions. Hereby, the final solutions must address several demands of various stakeholders within the internal crowd. In this context, the solutions might be congruent or contradictory, which implies a certain coordination process across different organizational units. Therefore, the common IT-facilitated platform serves 
as a technical mediator to distribute tasks, share information, and consolidate partial solutions. "Although the internal system structures all processes, there are many different features and applications to be considered." (CWIO)

Nevertheless, internal crowd work technically opens new possibilities for hitherto unknown work arrangements. For example, employees participate in an internal software development project via the platform besides their regular tasks. Internal crowd work multiplies the potential for globally distributed collaboration, joint performance of tasks, and independent allocation of resources. The employees, as internal crowd workers, can freely decide when, how, and with whom to perform certain tasks. As a result, the technical possibilities (e.g., platform functions, interfaces, and software) get even more deeply interwoven with human resources into a complex network of socio-technical elements.

4.1.3. Multi-directional inheritance. Another effect of this new diverse pool of internal labor describes the fact that all involved employees, based on their personal and professional backgrounds, form the internal crowd work initiative. By posting tasks, collaborating, and providing separate solutions via the platform, the employees themselves primarily shape the working conditions as well as the work contents. As one mentioned: "The implementation of projects as well as the processes change which is why the internal tool is constantly adjusted each new release." (CW1) Thus, the embedding of new work context is influenced by the individual elements of the internal crowd, rather than the inherent purpose and structures from traditional hierarchies.

However, one can observe a reversed effect since the overarching internal crowd work initiative, in turn, directly and indirectly reshapes the work within the single organizational units of the employees. On the one hand, since any employee invests time for participating, they need to adjust their own time and resource management. Activities within internal crowd work might be closely aligned with the original tasks and duties of the organizational unit. On the other hand, internal crowd work indirectly influences the previous work habits of the employees. As part of their participation, the employees gather impressions of different working methods, processes, and even tools of other teams, units, or organizations. These experiences, in turn, affect the previous work of the employees since they may adopt certain habits or procedures. In addition, the platform itself set out a framework for action with its functionalities, interfaces, and process guidelines that affects daily work. For example, within an internal software testing initiative, the participating employees are called to always submit their bug reports in a specific format until Wednesday afternoon. Thereby, the internal crowd work initiative determines work within its sociotechnical sub-systems.

4.1.4. Continual negotiation. Since internal crowd work allows for a group-wide inter-organizational collaboration, it is also applied as a decision-making tool. In this context, internal crowd work is used to collectively evaluate or vote certain tasks, practices as well as solutions. For example, all involved employees within a software roll-out project are asked for their consent via the crowd work platform before the next steps are done. The internal crowd work initiative constitutes a democratic tool whereby decision-makers can legitimize their decision based on employees' assessments. Thus, a participant described: "Somehow the platform is also used as a veto-tool for certain decisions. We can vote and decide general issues with the platform." (CW2) In some cases, the collaborative decision-making processes are divided on a regional basis with respect to the scope and relevance of the single tasks and solutions. Hence, decisions are first made on a local level (within one organization of the group) before being passed on a regional level (organizations within a specific region, e.g., Europe) and are finally made on a global level (group-wide). Thus, internal crowd work takes various goals, standards, and values of heterogeneous employees into account.

Further, the dynamic nature of internal crowd work evokes continual optimization and progress. The purpose of internal crowd work is to collaboratively solve certain tasks of general importance to improve the organization. In fact, the employees involved strive for ongoing optimization of products, structures, or processes based on mutual agreements in the internal crowd. For example, within an initiative on a realignment of the company's overall market strategy, the participating employees, executives and even the board negotiate changes and next steps via the internal platform.

4.1.5. Perception of work. The participation in internal crowd work initiatives affects the employees' perception of work in general. Due to internal crowd work, the employees feel much more selfdetermination regarding their work routine. They can freely decide when and how much tasks to perform in the internal crowd. Thus, the participating employees determine the working time, the number of tasks, and their chosen procedure. 


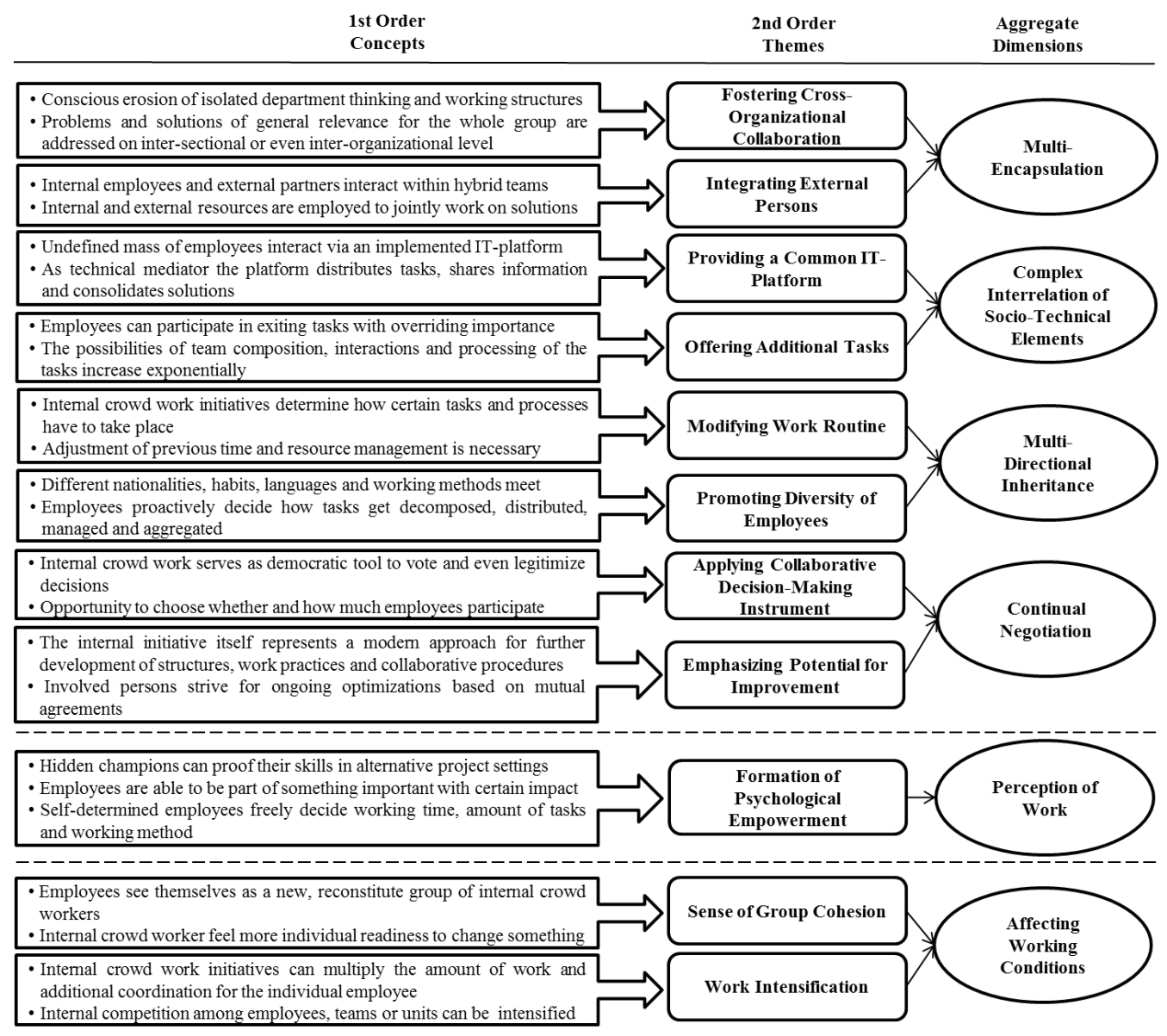

Figure 1. Data structure

As a result, they perceive a new sense of freedom that enables them to reorganize the daily business by their own. "Everybody has access to it, everybody has a look into the tool whenever he wants to, and everybody can give their comments to problems and participate voluntarily." (CW5) an employee reported.

Furthermore, through internal crowd work, employers can detect untapped talents and give them a chance to prove themselves. Hence, employees who previously received less attention can show their competence in various internal crowd work tasks according to their skills and abilities.

In addition, these employees can choose tasks that are consistent with their individual goals, values, and interests. Besides the daily routines, the employees thus experience tasks of specific meaning. Another sense of control due to internal crowd work is the possibility to participate in overarching tasks that are partially of group-wide relevance. Thereby, the employees feel that they can influence certain activities and outcomes in their organization.
4.1.6. Affecting working conditions. In sum, the implementation of crowd work changes the individual experience of work from an employee's perspective and further affects their working conditions. However, one can observe contrary effects of internal crowd work on the work environment. Employees develop some sense of team spirit, a common bond. Employees who regularly work in the internal crowd and collaboratively perform tasks are likely to feel a certain bond and further see themselves as a unit. Thus, one interviewee stated: "Sure, one gets to know each other much more easily and even socialize across all divisions via the platform." (CW15) This may be due to the voluntary nature of internal crowd work and the possibility to choose tasks based on personal interests. Further, it enables free development of an employeefriendly work environment. The employee's mindset might change and their individual readiness for a change in the organization or group might rise. Due to the implementation of internal crowd work as a new form of work organization, the participating employees 
experience a positive attitude towards future amendments.

However, we observed contrary effects of internal crowd work on the work environment. The employees' workload rises by performing internal crowd work tasks. The employees need to reorganize their time and resource management regarding these additional tasks. As a result, their daily workload changes and certain peaks might occur. "Sometime the whole coordination process of tasks falls on the shoulders of two or three persons. That could be very stressful." (CW2)

Further, internal crowd workers are in constant competition to perform the most interesting or important tasks. A special form of internal competition emerges in which employees strive for recognition by colleagues and executives.

\subsection{A model of internal crowd work as source of empowerment}

According to Gioia et al. [33], although the data structure is very important, it is nonetheless the static picture of a dynamic phenomenon. Hence, we develop an inductive model that is grounded in the data of the internal crowd workers and captures their perception in theoretical terms. Our theoretical model shows the dynamic relations amongst the emergent concepts which describe the emergence of empowerment in internal crowd work settings (see Figure 2).

The identified structural environment indicates a nexus to the actual perception of internal crowd workers. One can observe an enhanced collaboration of employees across organizational boundaries. This seems to have a positive effect on the psychological empowerment. By opening traditional barriers and structures, employees thereby organize their own work in a more self-determined manner. "What we do not do via this platform, is connecting people with many small problems, but rather big issues that have been already experienced or even solved by another one." (CW3)

Further, we believe that the integration of external experts into the internal initiatives broadens the employees' horizon and even their scope of action. "Sometimes we get very good solutions from IBM who is the IT partner who knows most about changes and sometimes we get a really rubbish ones." (CW4) Hence, employees acting in multi-encapsulated contexts like internal crowd work are more likely to act more self-determined than others. Thus, we assume:

Proposition 1: An ongoing multi-encapsulation positively affects an employee's psychological empowerment.
Moreover, we observed that the usage of a common IT-facilitated platform leads to more interaction within the internal crowd compared to traditional work settings. By sharing resources and information as well as coordinating work via this platform, single employees feel more autonomous in planning and scheduling work. Their actions within the internal crowd must be compatible with one another to find valuable solutions for the whole group. "Goals and subtasks are specified for every participant and finally linked to an overarching task via this tool." (CW11)

In addition, the amount of potential work and participation rises due to internal crowd work whereby employees can prove themselves in joint tasks. In sum, we assume that due to this increase in complexity between humans and technology the work of employees gains in meaning. For example, internal crowd workers reported that mastering the new functions and possibilities of the IT-platforms had shown them a certain importance of their work. Thus, employees feel more capable to perform demanding tasks. Hence, we believe:

Proposition 2: The complex interrelations of sociotechnical elements positively affect an employee's psychological empowerment.

Regarding certain effects on daily work, we observed that participants adjust their routines, although to differing degrees, depending on whether their superior sets special basic conditions or whether they are entirely free to plan task performance within the crowd. The employee must define specific periods and modify their usual workflow either way. For example, some employees have deliberately set Wednesday afternoon as a slot to perform internal crowd work. Therefore, internal crowd work initiatives shape daily work routines within the single work units. In contrast, the employees themselves as well as their work routines and habits form the internal crowd work, as some report: "Due to various cultures, languages and own manners, problems are discussed in different ways in this collaboration." (CWI)

Thus, we believe that internal crowd work derives purpose, goals, and structure from its social subsystems, but simultaneously shapes them as an overarching scaffold. The ability to reorganize certain parts of their own work routine and proactively design the internal crowd work enables employees to feel more self-determined. Employees find themselves in a novel overarching work setting that includes more freedom and creative self-expression. Hence, we assume:

Proposition 3: The multi-directional inheritance positively affects an employee's psychological empowerment. 


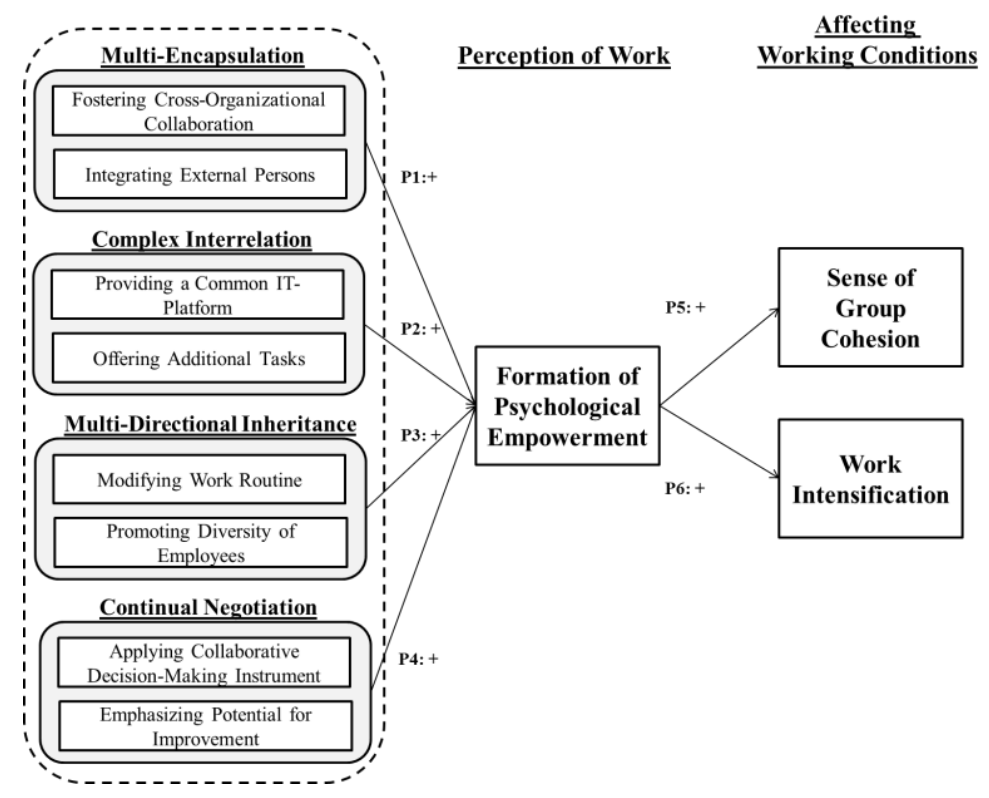

Figure 2. Model of psychological empowerment in internal crowd work

With the implementation of internal crowd work, the employer provides a technical infrastructure that enables its employees to proactively participate. Furthermore, they can share their opinions about new ideas and assessments of subtasks group-wide. Additionally, internal crowd work itself is an approach that leverages the untapped potential to improve the organization. One internal crowd worker reported: "So, if this platform is more focused on solutions we will have like a menu of solutions. It is like a proactive way to find your solutions." (CW6)

Based on continual negotiation between all involved parties, internal crowd work provides great potential to proactively participate in tasks that might lead to important future solutions. Thereby, internal crowd work makes employees realize that they can influence decisions, processes, and activities within the group to a certain extent. The involved employees might see themselves as decision-makers who can change certain things in an iterative process of mutual consultation. Hence, we assume:

Proposition 4: The continual negotiation positively affects an employee's psychological empowerment.

In most work contexts, including internal crowd work, more empowered employees experienced their environment in a different way. On the one hand, internal crowd workers are more likely to feel as one group or team since they jointly perform tasks of interorganizational relevance within an own Neo-STS. In this context, one interviewee stated: "With the implementation of this tool and this process, a network was formed. Thereby, a global information platform with all participants, who see themselves as a certain group, has emerged." (CW1)

On the other hand, we assume that employees who are empowered through internal crowd work are more willing to support fundamental changes within the group. Furthermore, they see themselves as being able to successfully accomplish changes as well as other opportunities to participate in a change process. Thus, we propose:

Proposition 5: The psychological empowerment positively affects an employee's sense of group cohesion.

However, there are also stress factors that might occur within internal crowd work. Although the employees perform tasks voluntarily, any activity or effort within the internal crowd leads to additional workload. One internal crowd worker stated that due to the number of new interfaces and applications, "some sort of interdependency arises which forces the user to work in a certain way." (CW10) Thus, based on their newly attained autonomy and self-determination, there might be risks of work stress and self-exploitation as well.

In addition, since any empowered employee applies for the most prestigious and interesting tasks, internal competition among the workforce will be enhanced. In some internal crowd work settings, the participating employees gain internal recognition that might have positive effects on employee assessment and even promotions. Hence, we believe:

Proposition 6: The psychological empowerment will increase an employee's work intensification. 


\section{Discussion}

To our knowledge, this study is one of the first to investigate the basics of internal crowd work from an individual's perspective. Thus, our research project provides three main theoretical contributions. First, our expected results detail and extend the findings of existing crowd work research [7] by addressing the individual and examining the perception of work. Hence, according to Deng et al. [12], we provide an explanation of how the internal workforce might get empowered due to the implementation of internal crowd work. Second, we expand the scope of Neo-STS [15] by illustrating concrete structural effects of its components (e.g., multi-encapsulation) on the working conditions (increasing sense of group cohesion) through employees perception of work (formation of empowerment). At the same time, we contribute to prior research on empowerment $[22,24]$ by extending and refining structural antecedents as well as outcomes of empowerment within internal crowd work. As our model shows, structural antecedents enhance the formation of psychological empowerment and, thus, might increase employees' self-determination, meaning, competence, and impact. Third, we generate important new insights to work design [36] and collaborative team literature $[1,3]$ by providing valuable insights of internal crowd work from a company's perspective regarding the design of digital work settings. This hopefully encourages IS researchers to focus on appropriate design guidelines and elements that address the effects of our examined structural antecedents in further studies. For example, the findings suggest the implementation of an internal IT-platform that enables cross-organizational collaboration among employees and further allows them to work on overarching projects with external persons.

Our results are expected to provide a foundation for upcoming discussions on decent conditions in internal crowd work in companies (e.g., management and executives) and among policy makers (e.g., politicians and unions). As a main practical contribution, companies are enabled to adjust and reorganize their work structures regarding internal crowd work and to improve them in the sense of an empowermentoriented implementation. This means that companies should consciously promote performing certain tasks in these platform- and group-based as well as locationand time-independent voluntary work settings.

While our study provides some important contributions with respect to internal crowd workers' perception of work and their empowerment, we also acknowledge that our study has limitations, especially regarding the generalizability of our results. First, we developed our model using data from 16 interviewees in three companies that apply internal crowd work. Since we mainly interviewed employees, the important overall business perspective has been neglected. However, to be able to incorporate the company's perspective, future studies should, nevertheless, consider the views of administrators of the internal crowd work platforms as well as the management and executives of the companies. Thereby, one can analyze the effects on traditional business outcome variables like productivity or customer satisfaction. Second, in our theoretical model, we entirely consider qualitative data from our interviews. However, future studies can take up on our results and underline them based on quantitative results. Besides well-established work design instruments that quantitively measure the individuals perception [36], future research might analyze internal performance data (e.g., amount of cross-functional performed tasks, time on platform per person, additional working time due to internal crowd work tasks) to derive insights of how employees are empowered by internal crowd work initiatives.

\section{References}

[1] Sirmon, D.G., M.A. Hitt, and R.D. Ireland, "Managing firm resources in dynamic environments to create value: Looking inside the black box", Academy of Management Review, 32(1), 2007, pp. 273-292.

[2] Brynjolfsson, E. and A. McAfee, The second machine age: Work, progress, and prosperity in a time of brilliant technologies, WW Norton \& Company, 2014.

[3] Maruping, L.M. and M. Magni, "Motivating employees to explore collaboration technology in team contexts", MIS Quarterly, 39(1), 2015.

[4] Trainer, E.H., A. Kalyanasundaram, C. Chaihirunkarn, and J.D. Herbsleb, eds., How to hackathon: Socio-technical tradeoffs in brief, intensive collocation, ACM, 2016.

[5] Dery, K., I.M. Sebastian, and N. van der Meulen, "The digital workplace is key to digital innovation", MIS Quarterly Executive, 16(2), 2017.

[6] Durward, D., I. Blohm, and J.M. Leimeister, "Crowd work", Business \& Information Systems Engineering, 58(4), 2016, pp. 281-286.

[7] Zuchowski, O., O. Posegga, D. Schlagwein, and K. Fischbach, "Internal crowdsourcing: Conceptual framework, structured review, and research agenda", Journal of Information Technology, 31(2), 2016, pp. 166-184.

[8] Geiger, D. and M. Schader, "Personalized task recommendation in crowdsourcing information systemsCurrent state of the art", Decision Support Systems, 65, 2014, pp. 3-16. 
[9] Jette, A., A. Breck, and R. Johns, eds., Integrating balanced scorecard performance management with crowdsourced strategic planning, 2015.

[10] Vom Brocke, J., W. Maaß, P. Buxmann, A. Maedche, J.M. Leimeister, and G. Pecht, "Future work and enterprise systems", Business \& Information Systems Engineering, 2018, pp. 1-10.

[11] Deng, X.N. and K.D. Joshi, "Why individuals participate in micro-task crowdsourcing work environment: Revealing crowdworkers' perceptions", Journal of the Association for Information Systems, 17(10), 2016, p. 648.

[12] Deng, X., K.D. Joshi, and R.D. Galliers, "The duality of empowerment and marginalization in microtask crowdsourcing: Giving voice to the less powerful through value sensitive design", MIS Quarterly, 40(2), 2016, pp. 279302 .

[13] Liden, R.C., S.J. Wayne, and R.T. Sparrowe, "An examination of the mediating role of psychological empowerment on the relations between the job, interpersonal relationships, and work outcomes", Journal of Applied Psychology, 85(3), 2000, p. 407.

[14] Appelbaum, S.H., "Socio-technical systems theory: An intervention strategy for organizational development", Management Decision, 35(6), 1997, pp. 452-463.

[15] Winter, S., N. Berente, J. Howison, and B. Butler, "Beyond the organizational 'container': Conceptualizing 21st century sociotechnical work", Information and Organization, 24(4), 2014, pp. 250-269.

[16] Mumford, E., "The story of socio-technical design: Reflections on its successes, failures and potential", Information Systems Journal, 16(4), 2006, pp. 317-342.

[17] Bostrom, R.P. and J.S. Heinen, "MIS problems and failures: A socio-technical perspective, part II: the application of socio-technical theory", MIS Quarterly, 1977, pp. 11-28.

[18] Lyytinen, K. and M. Newman, "Explaining information systems change: A punctuated socio-technical change model", European Journal of Information Systems, 17(6), 2008, pp. 589-613.

[19] Rohrbeck, R., N. Thom, and H. Arnold, "IT tools for foresight: The integrated insight and response system of Deutsche Telekom Innovation Laboratories", Technological Forecasting and Social Change, 97, 2015, pp. 115-126.

[20] Bharati, P., W. Zhang, and A. Chaudhury, "Better knowledge with social media? Exploring the roles of social capital and organizational knowledge management", Journal of Knowledge Management, 19(3), 2015, pp. 456-475.

[21] Elmes, M.B., D.M. Strong, and O. Volkoff, "Panoptic empowerment and reflective conformity in enterprise systems-enabled organizations", Information and Organization, 15(1), 2005, pp. 1-37.

[22] Spreitzer, G.M., "Taking stock: A review of more than twenty years of research on empowerment at work", Handbook of Organizational Behavior, 2, 2008, pp. 54-72.
[23] Conger, J.A. and R.N. Kanungo, "The empowerment process: Integrating theory and practice", Academy of Management Review, 13(3), 1988, pp. 471-482.

[24] Spreitzer, G.M., "Psychological empowerment in the workplace: Dimensions, measurement, and validation", Academy of Management Journal, 38(5), 1995, pp. 14421465.

[25] Thomas, K.W. and B.A. Velthouse, "Cognitive elements of empowerment: An "interpretive" model of intrinsic task motivation", Academy of Management Review, 15(4), 1990, pp. 666-681.

[26] Gist, M.E. and T.R. Mitchell, "Self-efficacy: A theoretical analysis of its determinants and malleability", Academy of Management Review, 17(2), 1992, pp. 183-211.

[27] Deci, E.L., J.P. Connell, and R.M. Ryan, "Selfdetermination in a work organization", Journal of Applied Psychology, 74(4), 1989, p. 580.

[28] Ashforth, B.E., "The experience of powerlessness in organizations", Organizational Behavior and Human Decision Processes, 43(2), 1989, pp. 207-242.

[29] Myers, M.D. and M. Newman, "The qualitative interview in IS research: Examining the craft", Information and Organization, 17(1), 2007, pp. 2-26.

[30] Schultze, U. and M. Avital, "Designing interviews to generate rich data for information systems research", Information and Organization, 21(1), 2011, pp. 1-16.

[31] Suri, H., "Purposeful sampling in qualitative research synthesis", Qualitative Research Journal, 11(2), 2011, pp. 63-75.

[32] Rerup, C. and M.S. Feldman, "Routines as a source of change in organizational schemata: The role of trial-and-error learning", Academy of Management Journal, 54(3), 2011, pp. $577-610$.

[33] Gioia, D.A., K.G. Corley, and A.L. Hamilton, "Seeking qualitative rigor in inductive research: Notes on the Gioia methodology", Organizational Research Methods, 16(1), 2012, pp. 15-31.

[34] Alvesson, M. and D. Kärreman, "Constructing mystery: Empirical matters in theory development", Academy of Management Review, 32(4), 2007, pp. 1265-1281.

[35] Tracy, S.J., "Qualitative quality: Eight "big-tent" criteria for excellent qualitative research", Qualitative Inquiry, 16(10), 2010, pp. 837-851.

[36] Morgeson, F.P. and S.E. Humphrey, "The Work Design Questionnaire (WDQ): Developing and validating a comprehensive measure for assessing job design and the nature of work", Journal of Applied Psychology, 91(6), 2006, p. 1321. 